\title{
ARTICLE OPEN Diversity of $N$-acyl homoserine lactones in activated sludge detected by Fourier transform mass spectrometry
}

\author{
Ryo Honda (D) ${ }^{1}$, Phuong-Thanh Phan ${ }^{2}$, Tomohiro Tobino ${ }^{3}$, Sirilak Prasertkulsak ${ }^{4}{ }^{4}$, Smarch Panchavinin ${ }^{2}$, Phuc-Nguon Hong ${ }^{2}$, \\ Chanreaksmey Taing ${ }^{2}$, Mana Noguchi ${ }^{5}$, Wilai Chiemchaisri ${ }^{4}$ and Chart Chiemchaisri ${ }^{4}$
}

Quorum sensing is recently considered to play important roles in biological wastewater treatment processes. This study aimed to investigate diversity of $\mathrm{N}$-acyl homoserine lactones (AHL) among biological wastewater treatment processes and their locations. We analyzed and quantified $10 \mathrm{AHL}$ in activated sludge at wastewater treatment plants (WWTPs) by Fourier transform mass spectrometry (FTMS) and by bioassay on thin-layer chromatography (TLC). Sludge samples were taken at seven WWTPs in Japan and in Thailand, which were chosen to compare different process types including a pilot-scale membrane bioreactor process. Various AHL were detected in activated sludge, suggesting the presence of quorum sensing activity in many practical WWTPs. Detection of AHL by LC-FTMS was much more sensitive than by TLC bioassay, because TLC bioassay was implied to be affected by the presence of quorum quenching molecules in activated sludge. With LC-FTMS analysis, AHL, which has short straight chain in the acyl group, were more abundant. Especially, $\mathrm{C}_{4}-\mathrm{HSL}, \mathrm{C}_{7}-\mathrm{HSL}$, and $\mathrm{C}_{8}-\mathrm{HSL}$ were detected widely independent of locations and process types. $\mathrm{AO}$ processes had higher $\mathrm{AHL}$ productivity than other processes.

npj Clean Water (2019)2:11; https://doi.org/10.1038/s41545-019-0035-0

\section{INTRODUCTION}

Some microbes are known to secrete signal molecules to detect their population density, then activate their group behavior when the signal molecule reaches a threshold concentration. This phenomenon of microbial cell-to-cell communication, known as "quorum sensing", is recently considered to play a certain role in biological wastewater treatment processes. $^{1-4}$ Among various signal molecules reported so far, $\mathrm{N}$-acyl homoserine lactones (AHL) are known to be the main signal molecules of Gram-negative bacteria. The chemical structure of $\mathrm{AHL}$ comprises a homoserine lactone (HSL) moiety, linked to a variable acyl side chain. ${ }^{5}$ The length of acyl chain varies from 4 to 18 carbon atoms of straight chain structure or with side chain of 3-hydroxyacyl or 3-oxoacyl groups. $^{6-11}$ The various $\mathrm{AHL}$ are reported to trigger group behaviors, such as biofilm formation, production of extracellular polymeric substances (EPS), virulence factors, pigments, etc. ${ }^{2,10,12}$

Importance of quorum sensing in wastewater treatment has been reported in membrane bioreactor (MBR) processes. Degradation of quorum sensing signal molecules by acylase or specific bacteria, called "quorum quenching", is reported to be effective to reduce membrane fouling. ${ }^{13-17}$ This is probably because quorum sensing triggers production of EPS, which are the major foulant in MBR. ${ }^{18-20}$ However, among various species of $A H L$, it is still unclear what $\mathrm{AHL}$ species are important to induce microbial group behaviors that affect treatment performance and membrane fouling. Meanwhile, effects of quorum sensing on treatment performance in other biological wastewater treatment processes are still unknown. If quorum sensing stimulates EPS production as reported in MBR researches, it might enhance flocculation and improve settleability of activated sludge. However, role of quorum sensing in conventional wastewater processes, including whether it really occurs, has not been investigated much so far.

Detection of $A H L$ is one of the direct evidences on occurrence of quorum sensing. The popular methods to detect $A H L$ are bioassay using recombinant microbial reporter and liquid chromatography with tandem mass spectrometry (LC-MS/MS) after extraction by organic solvents, e.g., dichloromethane, ethyl acetate, chloroform. ${ }^{12}$ The microbial reporter assay is often used due to its simple and easier experimental procedures. ${ }^{17,21,22} \mathrm{~A}$ microbial reporter strain is designed to indicate color, luminance, or fluorescence responding to the presence of AHL. Microbial reporter strains that are often used in recent studies have a recombinant plasmid in which $L u x R$ homolog regulates lac $Z$ reporter to produce $\beta$-galactosidase. Presence of AHL can be detected with blue color formed by degradation of X-Gal with the produced $\beta$-galactosidase. A significant advantage of the bioassay is its high specificity. Owing to its principle of biological response, microbial reporter assay can accurately detect only AHL among various substances, which may also be contained in the extract. Identification of AHL species is also possible by combination with thin layer chromatography (TLC). ${ }^{21-23}$ However, accurate quantification of $\mathrm{AHL}$ concentrations is difficult from spot area calculation on TLC. LC-MS/MS is also applied to identify AHL species produced by pure culture of quorum sensing bacteria. ${ }^{12}$ To identify AHL species by LC-MS/MS, each AHL species is to be purified and concentrated by preparative high-performance liquid chromatography (HPLC). This method enables more reliable identification and is much more quantitative than bioassay.

\footnotetext{
${ }^{1}$ Faculty of Environmental Design, Kanazawa University, Kakuma-machi, Kanazawa 920-1192, Japan; ${ }^{2}$ Graduate School of Natural Science and Technology, Kanazawa University,

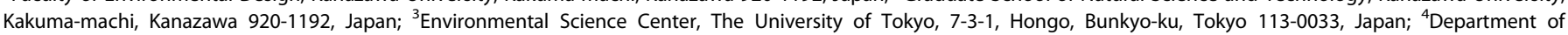

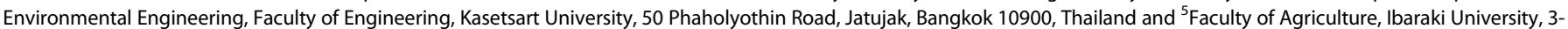
21-1, Chuuo, Ami, Inashiki, Ibaraki 300-0393, Japan

Correspondence: Ryo Honda (rhonda@se.kanazawa-u.ac.jp)
}

Received: 13 February 2018 Accepted: 13 March 2019

Published online: 02 May 2019 
However, it consumes much time when it targets various species of AHL or many samples.

Occurrence of quorum sensing in biological wastewater treatment is considered to be probable so far according to several reports on the presence of AHL in lab-scale MBRs. ${ }^{2,17}$ Presence of $\mathrm{AHL}$ in conventional activated sludge (CAS) processes has been reported only by Chong et al. ${ }^{24}$ who first reported the presence of AHL in activated sludge, and Tan et al. ${ }^{3}$ who detected and quantified $\mathrm{AHL}$ in an aerobic granule process. However, diversity of $\mathrm{AHL}$ in activated sludge and difference among treatment plants, process types, and cities are unknown yet. Moreover, knowledge on quantity of AHL species in activated sludge is still limited because most previous studies aimed at only detection of $\mathrm{AHL}$ but not quantification. One of the difficulties in detection of $\mathrm{AHL}$ in activated sludge is their low concentration. Typical AHL concentrations are at $\mathrm{ng} / \mathrm{L}$ levels in aerobic granules and in pure culture of quorum sensing bacteria. ${ }^{3,9,21}$ Therefore, to detect AHL in activated sludge, the sludge extract need to be concentrated at a high ratio up to $5000-10,000$ times. This high ratio of concentration makes it difficult to identify $\mathrm{AHL}$ among other micropollutants, which are also extracted and concentrated from the activated sludge. Fourier transform mass spectrometry (FTMS), which enables to obtain mass spectrum with very accurate mass-charge ratios $(\mathrm{m} / \mathrm{z})$, is recently developed and applied to

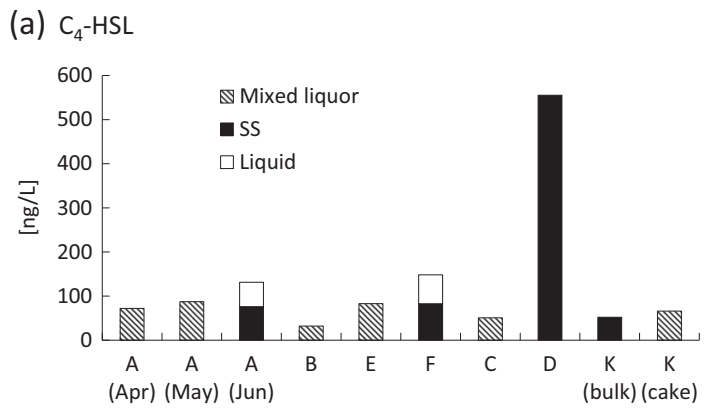

WWTP

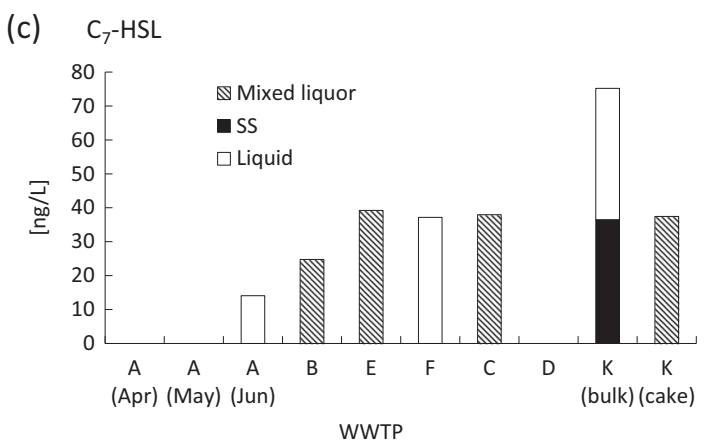

(e) $3 \mathrm{OH}-\mathrm{C}_{8}-\mathrm{HSL}$

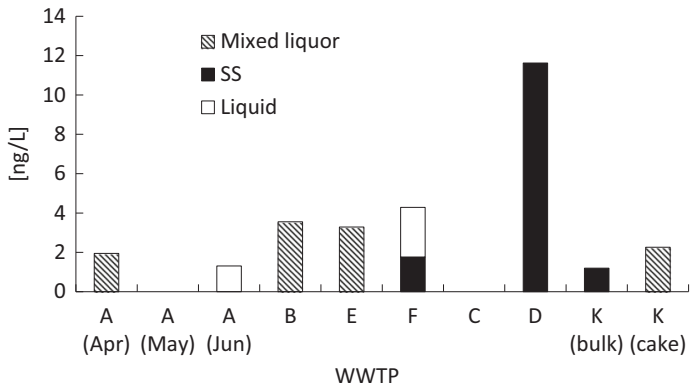

detection of profiling of organic matter in river water, organic matters in reclaimed water, and micropollutants in drinking water. ${ }^{25-27}$ The advantage of FTMS is that it enables to extract mass spectrum of target compounds by their accurate specific $\mathrm{m} / \mathrm{z}$. By using LC-FTMS, we can acquire a LC-mass spectrum with $\mathrm{m} / \mathrm{z}$, which is identical to each $\mathrm{AHL}$ species. ${ }^{5}$ Then we can identify and quantify a target $\mathrm{AHL}$ species in a sludge extract from its retention time and peak area. So far, LC-FTMS have been used for detection of $\mathrm{AHL}$ in pure cultures of bacterial isolates ${ }^{5,28}$; however, it has not been applied yet to detection of $\mathrm{AHL}$ in a complex culture of activated sludge.

Aiming to investigate diversity of quorum sensing in practical wastewater treatment, this study quantified various $\mathrm{AHL}$ species in activated sludge, which were taken from practical- and pilot-scale wastewater treatment plants (WWTPs) treating actual wastewater. In this study, LC-FTMS was applied for identification and quantification of AHL.

\section{RESULTS AND DISCUSSION}

Diversity of $A H L$ in activated sludge

A variety of $\mathrm{AHL}$ were detected by LC-FTMS in all sludge samples (Fig. 1). It was evidenced that various quorum sensing signal molecules are produced in activated sludge at practical-scale

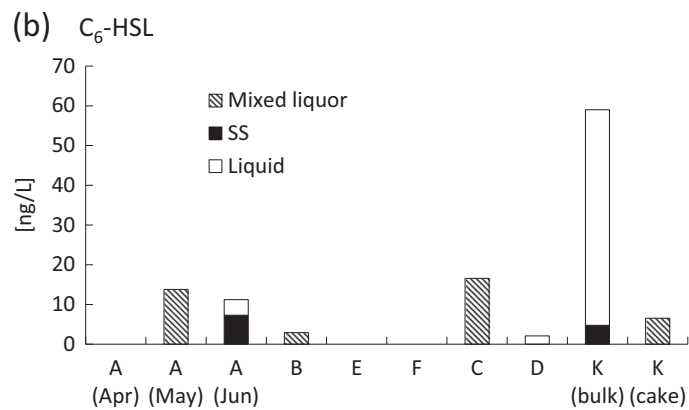

WWTP

(d) $\mathrm{C}_{8}-\mathrm{HSL}$

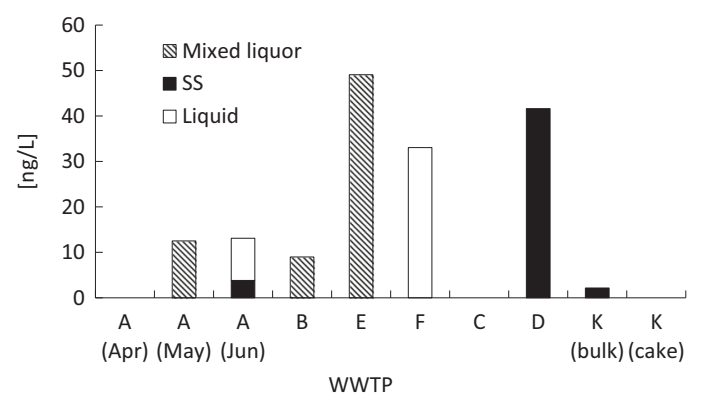

(f) $3 \mathrm{OH}-\mathrm{C}_{10}-\mathrm{HSL}$

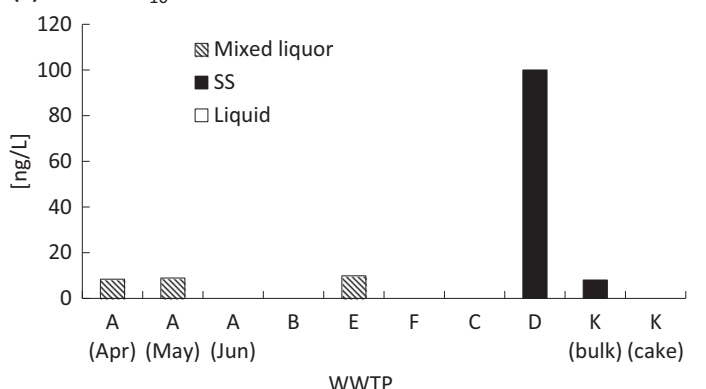

Fig. $1 \mathrm{~N}$-acyl homoserine lactone concentrations in activated sludge at wastewater treatment plants detected by liquid chromatography with tandem Fourier transform mass spectrometry 
WWTPs. Especially, some AHL were detected at higher concentration in SS phase than in liquid phase. Among the $10 \mathrm{AHL}$ species, $\mathrm{C}_{4}$ - $\mathrm{HSL}$ was found at all WWTPs. The concentration range of $\mathrm{C}_{4}{ }^{-}$ HSL were 50-150 ng/L at most WWTPs except D, where other AHL species were also detected at very high concentration. $\mathrm{C}_{8}-\mathrm{HSL}$, $3 \mathrm{OH}-\mathrm{C}_{8}-\mathrm{HSL}$, and $3 \mathrm{OH}-\mathrm{C}_{10}-\mathrm{HSL}$ were also detected in most WWTPs with a wide range of concentrations.

When $\mathrm{AHL}$ profile in liquid and SS phase were compared, $\mathrm{C}_{4^{-}}$ $\mathrm{HSL}$ and $3 \mathrm{OH}-\mathrm{C}_{8}-\mathrm{HSL}$ were likely to be detected at higher concentration in SS. Meanwhile, $\mathrm{C}_{7}-\mathrm{HSL}$ was present only in liquid phase except MBR. AHL found mostly in SS phase were relatively hydrophobic ones that have lower octanol-water partitioning coefficient $\left(K_{\mathrm{ow}}\right)$. Meanwhile, partitioning of relatively hydrophilic $\mathrm{AHL}$ were not likely to depend only on their hydrophilicity. Log $K_{\text {ow }}$ of $\mathrm{C}_{8}-\mathrm{HSL}$ and $3 \mathrm{OH}-\mathrm{C}_{10}-\mathrm{HSL}$ were higher than those of $\mathrm{C}_{7}-\mathrm{HSL}$, which were detected only in liquid phase. However, $\mathrm{C}_{8}-\mathrm{HSL}$ and $3 \mathrm{OH}-\mathrm{C}_{10}-\mathrm{HSL}$ were detected also in SS phase at high concentrations at WWTP D. Some hydrophilic AHL was detected in SS phase probably because sludge flocs have both types of binding sites, which have affinity to hydrophilic and hydrophobic substances. Therefore, $A H L$ produced in sludge flocs would be present both in SS and liquid phase. Meanwhile, hydrophilic AHL produced outside the flocs would be detected only in liquid phase. Consequently, detection of some AHL only in liquid phase implies that these $\mathrm{AHL}$ were produced by drifting microbes that were present apart from sludge flocs.

There are limited number of reports on $\mathrm{AHL}$ in activated sludge. Tan et al. ${ }^{3}$ detected $\mathrm{C}_{4}-\mathrm{HSL}, \mathrm{C}_{6}-\mathrm{HSL}, \mathrm{C}_{7}-\mathrm{HSL}, \mathrm{C}_{8}-\mathrm{HSL}$, 30- $\mathrm{C}_{6}-\mathrm{HSL}$, and $30-\mathrm{C}_{8}-\mathrm{HSL}$ in supernatant of aerobic granules by using LC-MS/ MS. Chong et al. ${ }^{24}$ also detected $\mathrm{C}_{7}-\mathrm{HSL}, \mathrm{C}_{10}-\mathrm{HSL}$, and $\mathrm{C}_{12}-\mathrm{HSL}$ in activated sludge and $\mathrm{C}_{4}-\mathrm{HSL}, \mathrm{C}_{6}-\mathrm{HSL}, \mathrm{C}_{8}-\mathrm{HSL}$, and $\mathrm{C}_{12}-\mathrm{HSL}$ from a culture of an Aeromonas sp. strain isolated from the sludge, using LC-FTMS and TLC bioassay. Recently, MBR sludge is more popular target of $\mathrm{AHL}$ analysis. In MBR sludge, $\mathrm{C}_{4}-\mathrm{HSL}, \mathrm{C}_{6}-\mathrm{HSL}, \mathrm{C}_{8}-\mathrm{HSL}$, and $30-\mathrm{C}_{8}-\mathrm{HSL}$ have been detected by $\mathrm{HPLC}^{14,29}$ and $\mathrm{C}_{6}-\mathrm{HSL}, \mathrm{C}_{8}-$ $\mathrm{HSL}$, and $\mathrm{C}_{10}$-HSL by TLC bioassay. ${ }^{16}$ However, concentrations of AHL in activated sludge were not quantified in those studies except by Tan et al., ${ }^{3}$ which analyzed supernatant of aerobic granules. Concentrations of $\mathrm{AHL}$ were also quantified in several studies on pure culture of $\mathrm{AHL}$-sensitive isolates., ${ }^{9,21}$ In those studies, concentrations of $\mathrm{AHL}$ were at $\mathrm{ng} / \mathrm{L}$ level. $\mathrm{AHL}$ concentrations in activated sludge was expected to be lower than those because other bacteria species which do not produce $\mathrm{AHL}$ also exist in the sludge. However, we have found that various $\mathrm{AHL}$ are present in activated sludge at practical-scale WWTPs at upto $100-200 \mathrm{ng} / \mathrm{L}$ at most WWTPs. That suggests that quorum sensing activity in activated sludge at most WWTPs is no less than reported in the past study. ${ }^{3}$ Most frequently detected AHL were the ones with relatively short side chain, such as $\mathrm{C}_{4}-\mathrm{HSL}, \mathrm{C}_{7}-\mathrm{HSL}$, $\mathrm{C}_{8}-\mathrm{HSL}$, and $3 \mathrm{OH}-\mathrm{C}_{8}-\mathrm{HSL}$. These $\mathrm{AHL}$ were also frequently detected in the past studies. ${ }^{14,16,24,29}$ Concentrations of $\mathrm{AHL}$ with no substitution in the side chain were higher at most sludge samples.

On the contrary, less number of AHL species were detected by TLC bioassay than by FTMS (Table S1). For example, $\mathrm{C}_{4}-\mathrm{HSL}$ and $\mathrm{C}_{6}$-HSL were not detected in any samples by bioassay although they were found widely by FTMS. One possible reason is higher detection limit in bioassay than in FTMS. However, detection limits by the bioassay in this study ranged from $1 \mathrm{pg} / \mathrm{L}$ to $1 \mathrm{ng} / \mathrm{L}$, which were much lower than concentrations detected by FTMS. Therefore, this underestimation of AHL by TLC bioassay is not because of low sensitivity. It is reported that quorum quenching, which hinders quorum sensing, also occurs in activated sludge. There are three mechanism of quorum quenching: inhibition in synthesis of signal molecules, degradation of signal molecules, and interference with signal receptor. ${ }^{30,31}$ The bioassay utilizes quorum sensing mechanism of the reporter strain. Therefore, if a sample extract contains any molecules that quenches quorum sensing, production of $\beta$-galactosidase by the reporter strain may not be triggered. As a result, $\mathrm{AHL}$ in the sample extract would be underestimated or not detected. Another possible reason is false positive in identification by FTMS. In FTMS analysis, an AHL species was identified by its retention time in LC and the representative $\mathrm{m} / \mathrm{z}^{5}$ In this study, the target range of the representative $\mathrm{m} / \mathrm{z}$ were set as strict as $\pm 5 \%$. Since $m / z$ is determined by the third decimal place in FTMS, the molecular formula of the mass spectrum is identical to the target AHL. Among peaks of the mass spectrum, the target $\mathrm{AHL}$ was identified by retention time within $\pm 0.1 \mathrm{~min}$ of the standard. We confirmed that there was no significant shift of retention time by the sample matrix from analytical tests with internal standards. Although the method employed in this study could not perfectly exclude other substances in sludge, LC-FTMS was more appropriate to detect a broader variety of AHL with higher sensitivity and quantitativity than TLC bioassay.

\section{Difference of AHL profiles among WWTPs}

From principal component analysis (PCA), difference of $\mathrm{AHL}$ profiles among WWTPs were characterized better when compared by $\mathrm{AHL}$ productivity, which was calculated as mass of $\mathrm{AHL}$ per mass of MLSS (Table 1). Three major principal components were found to contribute to $93.7 \%$ of total variance (Table 2). The first principal component $(\mathrm{PC} 1)$ had positive correlation with all $\mathrm{AHL}$

\begin{tabular}{|c|c|c|c|c|c|c|c|c|c|}
\hline WWTP & City & MLSS (mg/L) & SVI (mL/g) & $\mathrm{C}_{4}-\mathrm{HSL}$ & $\mathrm{C}_{6}-\mathrm{HSL}$ & $\mathrm{C}_{7}-\mathrm{HSL}$ & $\mathrm{C}_{8}-\mathrm{HSL}$ & $3 \mathrm{OH}-\mathrm{C}_{8}-\mathrm{HSL}$ & $3 \mathrm{OH}-\mathrm{C}_{10}-\mathrm{HSL}$ \\
\hline A (Apr) & Kanazawa & 1370 & 95 & 53.0 & - & - & - & 1.4 & 6.1 \\
\hline A (May) & Kanazawa & 1510 & 126 & 58.3 & 9.1 & - & 8.3 & - & 5.9 \\
\hline A (Jun) & Kanazawa & 1160 & 103 & 114 & 9.7 & 12.1 & 11.3 & 1.1 & - \\
\hline$E$ & Kanazawa & 700 & 329 & 119 & - & 55.7 & 70.4 & 4.7 & 14.1 \\
\hline$F$ & Kanazawa & 1650 & 170 & 90.6 & - & 22.4 & 20.1 & 2.6 & - \\
\hline C & Bangkok & 9000 & 49 & 5.7 & 1.8 & 4.2 & - & - & - \\
\hline D & Bangkok & 4231 & 80 & 132 & 0.49 & - & 9.9 & 2.8 & 23.6 \\
\hline K (bulk) & Bangkok & 11,450 & 83 & 4.6 & 5.2 & 6.5 & 0.19 & 0.11 & 0.71 \\
\hline K (cake) & Bangkok & 13,552 & 72 & 4.9 & 0.48 & 2.7 & - & 0.2 & - \\
\hline
\end{tabular}


Table 2. Component matrix of the major three principal components

\begin{tabular}{lrrl}
\hline AHL species & \multicolumn{1}{l}{ PC1 } & \multicolumn{1}{l}{ PC2 } & \multicolumn{1}{l}{ PC3 } \\
\hline $\mathrm{C}_{4}$-HSL & $\mathbf{0 . 7 4 9}$ & $-\mathbf{0 . 9 7 4}$ & -0.381 \\
$\mathrm{C}_{6}-\mathrm{HSL}$ & -0.232 & -0.347 & $-\mathbf{0 . 8 7 2}$ \\
$\mathrm{C}_{7}-\mathrm{HSL}$ & 0.440 & 0.458 & -0.291 \\
$\mathrm{C}_{8}-\mathrm{HSL}$ & 0.243 & 0.089 & -0.130 \\
$3 \mathrm{OH}-\mathrm{C}_{8}-\mathrm{HSL}$ & $\mathbf{0 . 7 4 9}$ & $-\mathbf{0 . 9 7 4}$ & -0.381 \\
$3 \mathrm{OH}-\mathrm{C}_{10}-\mathrm{HSL}$ & -0.232 & -0.347 & $-\mathbf{0 . 8 7 2}$ \\
Cumulative proportion to total variance & $58.5 \%$ & $77.0 \%$ & $93.7 \%$ \\
\hline
\end{tabular}

Note: Major components making up each principal component are shown in bold

$A H L N$-acyl homoserine lactone, HSL homoserine lactone, $P C$ principal component

(a) PC1 vs. PC2

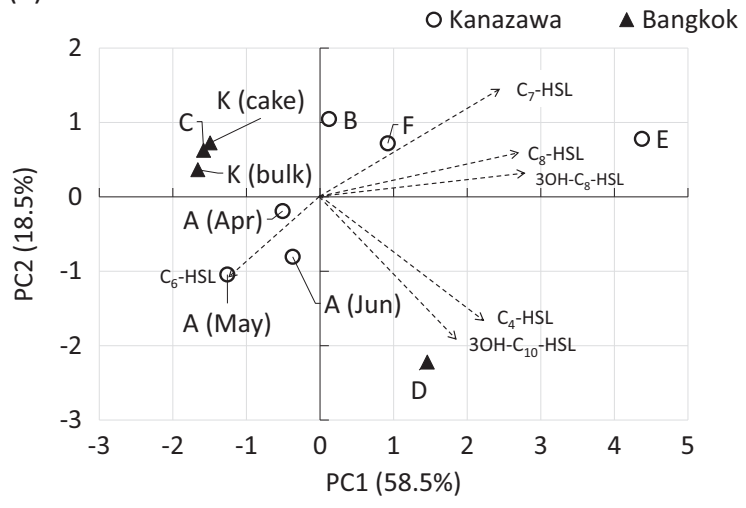

(b) PC1 vs. PC3

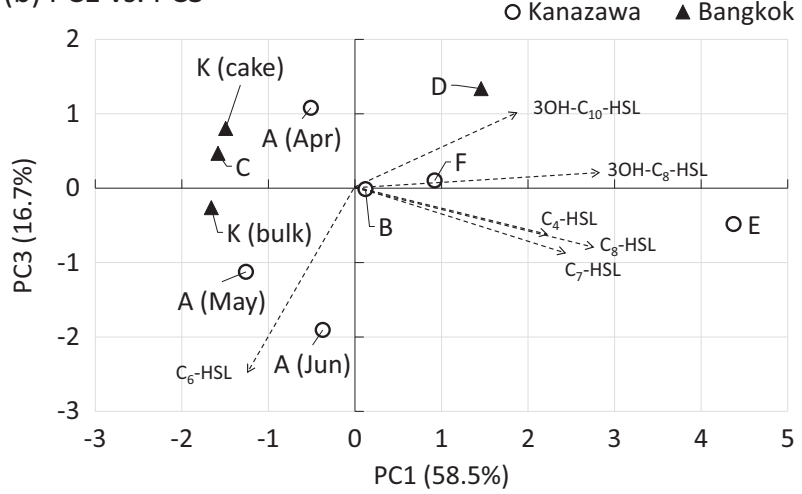

Fig. $2 \mathrm{~N}$-acyl homoserine lactones (productivity in mixed liquor of activated sludge at each wastewater treatment plant in Japan and in Bangkok plotted based on principal component analysis

except $\mathrm{C}_{6}-\mathrm{HSL}$. The PC1 was relatively higher in anoxic-oxic (AO) process ( $E$ and $F$ ) than other processes (Fig. 2). WWTP $D$ also had the positive PC1 value. At WWTP D, aeration had been stopped for a while due to unexpected power failure $10 \mathrm{~min}$ before sampling. Therefore, productivity of $\mathrm{C}_{4}-\mathrm{HSL}$ and $3 \mathrm{OH}-\mathrm{C}_{8}-\mathrm{HSL}$ probably became high after the sludge was exposed to anaerobic condition. The second principal component (PC2) correlated positively with productivity of $\mathrm{C}_{7}-\mathrm{HSL}$ but negatively associated with productivity of $\mathrm{C}_{4}-\mathrm{HSL}, \mathrm{C}_{6}-\mathrm{HSL}$ and $3 \mathrm{OH}-\mathrm{C}_{8}-\mathrm{HSL}$. The $\mathrm{PC2}$ values were negative at WWTPS $A$ and $D$ and positive at the others. The third principal component (PC3) was negatively contributed by productivity of $\mathrm{C}_{6}$-HSL. Three samples at WWTP A were taken to confirm fluctuation by sampling day and reliability of grab sampling. From the results of WWTP A, fluctuation by sampling day was limited in PC1 and PC2, although PC3 was more dependent on sampling days (Fig. 2). Therefore, $\mathrm{C}_{6}-\mathrm{HSL}$ was more likely to be affected by fluctuation of operating conditions and influent wastewater, e.g., temperature, retention time, wastewater quality, etc. Other AHL was probably more specific to the WWTP rather than daily conditions of operation and influent wastewater. The PC2 were very high at WWTP D and relatively higher in Japan than other WWTPs in Thailand. The PC3 did not have clear dependence on location nor process types, probably because PC3 depended more on daily conditions of the process, as observed in samples at WWTP A.

Difference of $\mathrm{AHL}$ productivity among process types was not significant due to the limited number of samples. However, higher values of $\mathrm{PC} 1$ in $\mathrm{AO}$ processes imply that $\mathrm{AHL}$ productivity is stimulated by the presence of anaerobic conditions. High PC1 value was also observed at WWTP $D$, where aeration was unexpectedly stopped owing to power failure $10 \mathrm{~min}$ before sampling. Therefore, sludge at WWTP D was also under similar conditions to sludge in an aeration tank of an AO process, in which sludge is under aerobic conditions after it has experienced anaerobic condition.

AHL productivity in bulk sludge and cake layer in the MBR process were not significantly different. Quorum sensing is reported to play an important role in membrane fouling and EPS production. ${ }^{13-17}$ However, it is unclear yet that the foulant production via quorum sensing is significant in bulk sludge or in cake layer. Quorum sensing has positive feedback mechanism to produce more signal molecules triggered by the presence of signal molecules at higher concentration than threshold. ${ }^{2}$ Therefore, if production of foulants via quorum sensing occurs in the cake layer, higher AHL productivity is expected in cake layer than in bulk sludge. Little difference in AHL productivity between bulk sludge and cake layer observed in this study suggest that foulant production via quorum sensing is not always significantly different between bulk sludge and cake layer.

Relations of AHL profiles with treatment performance

The primary factor to affect treatment performance of activated sludge is sludge settleability. Recently, effects of EPS in floc formation and stability were well discussed in aerobic granules. $3,32,33$ Two important roles of EPS in aerobic granules were suggested by Liu et al. ${ }^{33}$ : (i) altering surface charge of microbial cells and (ii) bridging neighboring cells. Hydrophobic EPS reduce surface charge of microbial cells and enhance floc formation and organization of microbial aggregates. EPS also function to maintain structure of granule by filling in intercellular spaces in microcolonies in the granule. If quorum sensing contributes to EPS production in activated sludge, it is also expected to enhance floc formation and stability to improve sludge settleability in a CAS process. Tan et al. ${ }^{3}$ reported that addition of $30-\mathrm{C}_{6}-\mathrm{HSL}, 3 \mathrm{O}-\mathrm{C}_{8^{-}}$ $\mathrm{HSL}$, and $3 \mathrm{O}-\mathrm{C}_{12}-\mathrm{HSL}$ increased EPS production and enhanced granulation of sludge. However, our observation of $\mathrm{AHL}$ in practical-scale WWTPs showed inconsistent trend with it. The sludge volume index (SVI) did not show clear correlation with productivity of most $\mathrm{AHL}$ species when they were plotted against each AHL productivity (Figure S1). Meanwhile, high productivity of $\mathrm{AHL}$ were observed at WWTPs $\mathrm{E}$ and $\mathrm{F}$ of $\mathrm{AO}$ processes, which had low settleability. This fact does not directly indicate mechanistic relations between $\mathrm{AHL}$ productivity and sludge settleability, because low sludge settleability is reported in low dissolved oxygen (DO) conditions in AO processes. ${ }^{34,35}$ However, the mechanism to cause low sludge settleablity under low DO conditions is not clearly understood yet. In this study, high production of several AHL were observed in $A O$ processes. Quorum sensing has been considered to positively affect sludge 
aggregation and settleablity. Our results implies that quorum sensing may be also associated with low sludge settleability. Various AHL species were found to be present in activated sludge in this study. That suggests that various group behaviors can be triggered by those signal molecules. To understand key roles of quorum sensing in activated sludge, further studies are needed to investigate response of activated sludge to each signal molecules.

\section{METHODS}

\section{Activated sludge samples}

Activated sludge samples were collected at four practical-scale WWTPs in Kanazawa, Japan, three practical-scale WWTPs, and one pilot-scale MBR plant in Bangkok, Thailand (Table 3). In Kanazawa, two WWTPs of CAS process and two WWTPs of AO process were chosen to compare AHL profiles between the processes. The sludge samples were also taken at WWTPs in Bangkok to investigate difference between the cities in different climate conditions. In Bangkok, three different processes were chosen for comparison, although samples were taken once at each WWTP due to limitation of sampling period. All the WWTPs treated municipal wastewater except the pilot-scale MBR, which treated wastewater from a university canteen. At WWTP A, samples were taken monthly from April until June, 2007 to observe the monthly change. Suspended solids (SS) concentrations and SVI of the collected sludge samples were analyzed within $24 \mathrm{~h}$ according to Eaton et al. ${ }^{36}$ The sludge samples collected in Kanazawa was immediately transferred on ice and stored at $4{ }^{\circ} \mathrm{C}$ until liquid extraction within $24 \mathrm{~h}$. The sludge samples collected in Bangkok was immediately transferred to laboratory and separated into liquid phase and SS part by centrifuge at $4200 \times g$ for $10 \mathrm{~min}$. The liquid phase of WWTP D was immediately sent to liquid extraction. The SS parts were freeze-dried until liquid extraction.

\section{Liquid extraction of $\mathrm{AHL}$}

$\mathrm{AHL}$ in sludge was extracted by liquid-liquid extraction with ethyl acetate according to Shaw et al. ${ }^{21}$ AHL was extracted from $900 \mathrm{~mL}$ of a sludge sample. The mixed liquor was used for extraction, except samples taken at WWTPs $A$ in June and D, F, and bulk sludge of WWTP K, which were separated into liquid phase and SS phase by centrifuge at $4200 \times g$ for $10 \mathrm{~min}$. The SS phase of the sample was destructed by sonication for $10 \mathrm{~min}$ and suspended in equal volume of pure water before liquid extraction. Both SS phase and liquid phase were extracted with equal volume of ethyl acetate. After the first extraction, the residue water phase was extracted again with equal volume of ethyl acetate. The solvent phase from the both extraction were mixed and concentrated by a rotary evaporator. The concentrated extract was dried up under nitrogen stream, then dissolved in $90 \mu \mathrm{L}$ of acetonitrile for storage.

To determine recovery ratio of $\mathrm{AHL}, 900 \mathrm{~mL}$ of standard solution of each $\mathrm{AHL}$ in water was also extracted with the same method and analyzed with LC-FTMS in the method described below. Concentrations of the standard AHL solutions for this recovery test were $100 \mathrm{ng} / \mathrm{L}$ (Table S2). The extraction was triplicated. The recovery ratio of each $\mathrm{AHL}$ was determined from average concentrations of AHL in the triplicated extracts.

\section{Detection of AHL by LC-FTMS}

Analysis of AHL extracts was performed using an LC system (Accela, Thermo Scientific, USA) coupled to an Orbitrap MS (Exactive, Thermo Scientific, USA), according to basic procedures by Cataldi et al. ${ }^{5}$ Chromatographic separation of the compounds was made using a TSKgel ODS-100V column $\left(2.0 \times 150 \mathrm{~mm}^{2}, 5 \mu \mathrm{m}\right.$ particle size; Tosoh Bioscience, Japan) maintained at $25^{\circ} \mathrm{C}$. MilliQ water containing $0.1 \%$ formic acid was used as eluent $A$ and $0.1 \%$ formic acid in acetonitrile as eluent $B$. The gradient profile was as follows: $50 \%$ A and $50 \%$ B for 5 min, linear increase of $B$ to $95 \%$ in $7 \mathrm{~min}$, held for $3 \mathrm{~min}$, linear decrease of B to $50 \%$ in $0.1 \mathrm{~min}$ and held for $5 \mathrm{~min}$. Separations were performed at a flow rate of $0.2 \mathrm{ml} /$ min to enter the electrospray ionization (ESI) source. AHLs (ranging from $\mathrm{C}_{4}$ to $C_{12}$, and for 3-oxo substituents and 3-hydroxy substituents) were detected by positive ion mode with the conditions in ESI source of: spray voltage, $4.5 \mathrm{kV}$; sheath gas, 50 (arbitrary units); auxiliary gas, 10 (arbitrary units); sweep gas, 0 (arbitrary units); capillary temperature, $300^{\circ} \mathrm{C}$; capillary voltage, $42.5 \mathrm{~V}$; tube-lens voltage, $85 \mathrm{~V}$; skimmer voltage, $18 \mathrm{~V}$. Full-scan mass spectra were ranged from $\mathrm{m} / \mathrm{z} 100$ to 400 . The limit of detection for each AHL was $0.1-1 \mu \mathrm{g} / \mathrm{L}$. A sample was prepared as follows. The extracted

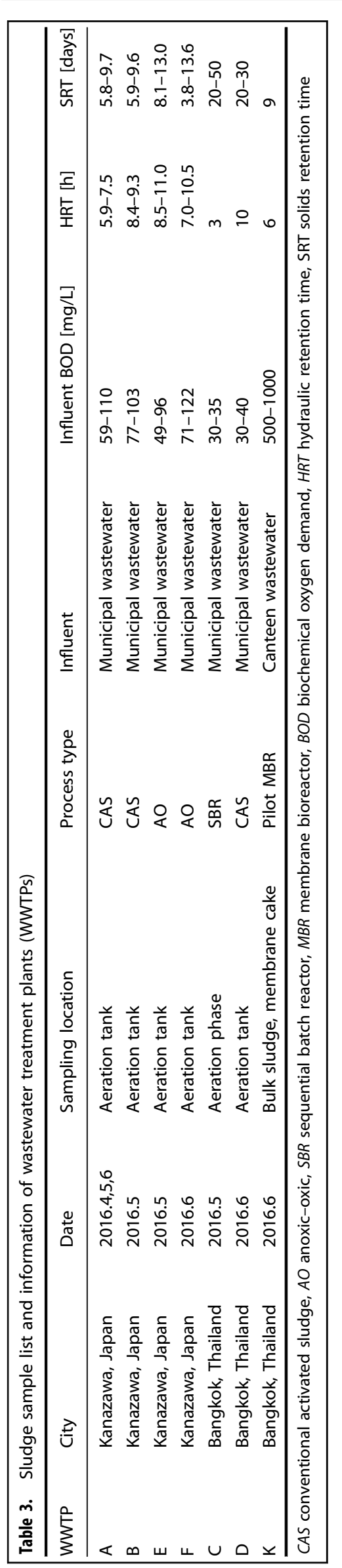


AHL from the supernatant and suspended solid phases were re-suspended in $90 \mu \mathrm{l}$ acetonitrile to bring all samples to a $10,000 \times$ volume equivalent extract concentration and then diluted by $5-15$ times before being filtered through a $0.45-\mu \mathrm{m}$ filter prior to FTMS analysis. Data acquisition and analysis were accomplished using the Xcalibur software (version 2.3 Thermo Electron). Identification and quantification of target compounds were performed using the accurate mass of the protonated molecule ([M $+\mathrm{H}^{+}$) within a mass window of $5 \mathrm{ppm}$ and characteristic retention times of the target AHL. The retention time of $L C$ and $\mathrm{m} / \mathrm{z}$ values used for identification of each $\mathrm{AHL}$ is shown in Table 4. External calibration curves were made by analyzing standard AHL chemicals dissolved in acetonitrile for 10-point calibration in the concentration range of $0-2000 \mu \mathrm{g} / \mathrm{L}$ and used for the calculation of AHL concentrations in sample extracts. A concentration of each $\mathrm{AHL}$ in a sludge sample was determined from the concentration in a sample extract and recovery ratio in liquid extraction as shown in Table S2. In this study, $30-\mathrm{C}_{6}-30-\mathrm{C}_{8^{-}}, 3 \mathrm{O}-\mathrm{C}_{10^{-}}$, and $3 \mathrm{O}-\mathrm{C}_{12}-\mathrm{HSL}$ were not discussed owing to their low recovery.

\section{Detection of AHL by TLC bioassay}

Ten microliter of a sample extract were spotted on $C_{18}$ reversed-phase TLC aluminum sheets (TLC Silica gel $60 \mathrm{RP}-18 \mathrm{~F}_{254 \mathrm{~s}}, 20 \times 20 \mathrm{~cm}^{2}$, MerckMillipore, USA) and allowed to dry at room temperature. A TLC chamber was filled with $60 \%(\mathrm{v} / \mathrm{v})$ methanol solution as the mobile phase and left for $1 \mathrm{~h}$ to ensure saturation. The plates were then developed in the mobile phase for $3 \mathrm{~h}$. After the solvent front had migrated to within $2 \mathrm{~cm}$ of the top of the chromatogram, the plate was removed from the chromatography tank and dried at room temperature.

The reporter strain Agrobacterium tumefaciens NTL4 (pZLR4) ${ }^{22}$ was cultured on a shaker to the late exponential phase at $28^{\circ} \mathrm{C}$ in LB medium supplemented with $15 \mathrm{mg} / \mathrm{mL}$ of gentamicin. The $40 \mathrm{~mL}$ of culture was added to $80 \mathrm{~mL}$ of the LB medium containing $1.8 \mathrm{~g}$ of agar and $60 \mu \mathrm{g} / \mathrm{mL}$ of 5-bromo-4-chloro-3-indolyl- $\beta$-D-galacto-pyranoside (X-Gal), then kept at $45^{\circ} \mathrm{C}$. The LB agar containing the reporter strain culture was spread over the developed TLC plate. After the agar had solidified, the plates were incubated at $28^{\circ} \mathrm{C}$ for $24-48 \mathrm{~h}$ in a sterilized closed plastic container. If the sample produced or contained $\mathrm{AHL}$, blue spots were detected by the reporter strain due to X-gal hydrolysis, which was induced by the expression of $\beta$-galactosidase. ${ }^{37}$

Each AHL compound was identified by its retention factor $R_{\mathrm{f}}$, which was calculated by:

$R_{\mathrm{f}}=\frac{a}{b}$

where $a$ is the distance from the starting point to the center of the spot and $b$ is the distance from the starting point to the solvent front. According to Shaw et al., ${ }^{21}$ diameter of each spot were linear over the log10 of the concentration. The diameter of each spot was calculated from the spot area based on pixel counting of the blue spots with Photoshop CC 2015 (Adobe, USA). Blue color components were extracted from the image, then the extracted image of each spot were cut and binarized by threshold that matches well with the overlaid color image of the spot on the TLC plate. The area of each spot was calculated by counting positive pixels in the binarized spot image. A representative diameter of each spot was calculated assuming the spot is a circle. AHL concentrations of a sample were calculated from a ratio of the representative diameter to the $\log 10$ of the concentration of the standard solutions. Detection limit of each AHL species was tested with standard solutions.

Multivariate analysis

PCA was performed with R Studio version 1.1.456 by using normalized datasets of AHL productivity, which was calculated as the amount of AHL per unit weight of sludge.

\section{DATA AVAILABILITY}

The data that support the findings of this study are available from the corresponding author upon reasonable request.

\section{ACKNOWLEDGEMENTS}

This study was supported by the JSPS Grant-in-Aid for Young Scientists A (Grant No. 15H05535), Fostering Joint International Research (Grant No. 16KK0146), and Kurita 
Water and Environment Foundation. We appreciate Kanazawa City and Bangkok Metropolitan for their cooperation in sampling at wastewater treatment plants.

\section{AUTHOR CONTRIBUTIONS}

R.H. contributed to plan and design of this research, data interpretation, and writing the paper. P.-T.P. conducted most part of sample collection in Kanazawa, sample analysis, data interpretation, and contributed to drafting the paper. S.P., P.-N.H, C.T., and M.N. contributed to sample collection, analysis, and data interpretation. T.T. contributed to design of LC-FTMS analysis, data interpretation, and co-writing the paper. S.P., W.C., and C.C. contributed to sample collection and pretreatment in Bangkok.

\section{ADDITIONAL INFORMATION}

Supplementary information accompanies the paper on the npj Clean Water website (https://doi.org/10.1038/s41545-019-0035-0).

Competing interests: The authors declare no competing interests.

Publisher's note: Springer Nature remains neutral with regard to jurisdictional claims in published maps and institutional affiliations.

\section{REFERENCES}

1. Ren, T. T., Yu, H. Q. \& Li, X. Y. The quorum-sensing effect of aerobic granules on bacterial adhesion, biofilm formation, and sludge granulation. Appl. Microbiol. Biotechnol. 88, 789-797 (2010).

2. Siddiqui, M. F., Rzechowicz, M., Harvey, W., Zularisam, A. W. \& Anthony, G. F. Quorum sensing based membrane biofouling control for water treatment: a review. J. Water. Eng. 7, 112-122 (2015).

3. Tan, C. H. et al. The role of quorum sensing signalling in EPS production and the assembly of a sludge community into aerobic granules. ISME J. 8, 1186-1197 (2014).

4. Zhang, W. \& Li, C. Exploiting quorum sensing interfering strategies in gramnegative bacteria for the enhancement of environmental applications. Front. Microbiol. 6, 1-15 (2016).

5. Cataldi, T. R. I., Bianco, G. \& Abate, S. Profiling of N-acyl-homoserine lactones by liquid chromatography coupled with electrospray ionization and a hybrid quadrupole linear ion-trap and Fourier-transform ion-cyclotron-resonance mass spectrometry (LC-ESI-LTQ-FTICR-MS). J. Mass. Spectrom. 43, 82-96 (2008).

6. Fuqua, C. \& Greenberg, E. P. Signalling: listening in on bacteria: acyl-homoserine lactone signalling. Nat. Rev. Mol. Cell Biol. 3, 685-695 (2002).

7. Marketon, M. M., Gronquist, M. R., Eberhard, A. \& González, J. E. Characterization of the Sinorhizobium meliloti $\operatorname{sinR} / \operatorname{sinl}$ locus and the production of novel $\mathrm{N}$-acyl homoserine lactones. J. Bacteriol. 184, 5686-5695 (2002).

8. Schaefer, A. L. et al. A new class of homoserine lactone quorum-sensing signals. Nature 454, 595-599 (2008).

9. Thiel, V., Kunze, B., Verma, P., Wagner-Döbler, I. \& Schulz, S. New structural variants of homoserine lactones in bacteria. Chembiochem 10, 1861-1868 (2009).

10. Galloway, W. R. J. D., Hodgkinson, J. T., Bowden, S. D., Welch, M. \& Spring, D. R. Quorum sensing in Gram-negative bacteria: small-molecule modulation of AHL and Al-2 quorum sensing pathways. Chem. Rev. 111, 28-67 (2011).

11. Savka, M. A., Le, P. T. \& Burr, T. J. LasR receptor for detection of long-chain quorum-sensing signals: identification of $\mathrm{N}$-acyl-homoserine lactones encoded by the avsl locus of Agrobacterium vitis. Curr. Microbiol. 62, 101-110 (2011).

12. Brelles-Mariño, G. \& Bedmar, E. Detection, purification and characterisation of quorum-sensing signal molecules in plant-associated bacteria. J. Biotechnol. 91, 197-209 (2001)

13. Jiang, W., Xia, S., Liang, J., Zhang, Z. \& Hermanowicz, S. W. Effect of quorum quenching on the reactor performance, biofouling and biomass characteristics in membrane bioreactors. Water Res. 47, 187-196 (2012).

14. Kim, S. R. et al. Biofouling control with bead-entrapped quorum quenching bacteria in membrane bioreactors: physical and biological effects. Environ. Sci. Technol. 47, 836-842 (2013).

15. Nahm, C. H. et al. Application of quorum quenching bacteria entrapping sheets to enhance biofouling control in a membrane bioreactor with a hollow fiber module. J. Membr. Sci. 526, 264-271 (2017).

16. Oh, H. S. et al. Control of membrane biofouling in MBR for wastewater treatment by quorum quenching bacteria encapsulated in microporous membrane. Environ. Sci. Technol. 46, 4877-4884 (2012).

17. Yeon, K.-M. et al. Quorum sensing: a new biofouling control paradigm in a membrane bioreactor for advanced wastewater treatment. Environ. Sci. Technol. 43, 380-385 (2009).
18. Kimura, K., Ogyu, R., Miyoshi, T. \& Watanabe, Y. Transition of major components in irreversible fouling of MBRs treating municipal wastewater. Sep. Purif. Technol. 142, 326-331 (2015).

19. Lin, $\mathrm{H}$. et al. A critical review of extracellular polymeric substances (EPSs) in membrane bioreactors: characteristics, roles in membrane fouling and control strategies. J. Membr. Sci. 460, 110-125 (2014).

20. Yun, M.-A. et al. Characterization of biofilm structure and its effect on membrane permeability in MBR for dye wastewater treatment. Water Res. 40, 45-52 (2006).

21. Shaw, P., Ping, G. \& Daly, S. Detecting and characterizing $\mathrm{N}$-acyl-homoserine lactone signal molecules by thin-layer chromatography. Proc. Natl Acad. Sci. 94 6036-6041 (1997).

22. Cha, C., Gao, P., Chen, Y. C., Shaw, P. D. \& Farrand, S. K. Production of acylhomoserine lactone quorum-sensing signals by gram-negative plant-associated bacteria. Mol. Plant Microbe Interact. 11, 1119-1129 (1998).

23. Wood, D. W., Gong, F., Daykin, M. M., Williams, P. \& Pierson, L. S. N-Acylhomoserine lactone-mediated regulation of phenazine gene expression by Pseudomonas aureofaciens 30-84 in the wheat rhizosphere. J. Bacteriol. 179, 7663-7670 (1997).

24. Chong, G., Kimyon, O., Rice, S. A., Kjelleberg, S. \& Manefield, M. The presence and role of bacterial quorum sensing in activated sludge. Microb. Biotechnol. 5 621-633 (2012).

25. Conley, J. M. et al. Comparison of in vitro estrogenic activity and estrogen concentrations in source and treated waters from $25 \mathrm{U}$. S. drinking water treatment plants. Sci. Total Environ. 579, 1610-1617 (2017).

26. Phungsai, P., Kurisu, F., Kasuga, I. \& Furumai, H. Molecular characterization of low molecular weight dissolved organic matter in water reclamation processes using Orbitrap mass spectrometry. Water Res. 100, 526-536 (2016).

27. Stenson, A. C., Marshall, A. G. \& Cooper, W. T. Exact masses and chemical formulas of individual suwannee river fulvic acids from ultrahigh resolution electrospray ionization Fourier transform ion cyclotron resonance mass spectra. Anal. Chem. 75, 1275-1284 (2003).

28. Cataldi, T. R. I., Bianco, G. \& Abate, S. Accurate mass analysis of N-acylhomoserine-lactones and cognate lactone-opened compounds in bacterial isolates of Pseudomonas aeruginosa PAO1 by LC-ESI-LTQ-FTICR-MS. J. Mass. Spectrom. 44, 182-192 (2008).

29. Waheed, H. et al. Microbial population dynamics and profiling of quorum sensing agents in membrane bioreactor. Int. Biodeterior. Biodegrad. 113, 66-73 (2016).

30. Huang, J. et al. Acyl-homoserine lactone-based quorum sensing and quorum quenching hold promise to determine the performance of biological wastewater treatments: an overview. Chemosphere 157, 137-151 (2016).

31. Shi, Y. et al. Exploiting extracellular polymeric substances (EPS) controlling strategies for performance enhancement of biological wastewater treatments: an overview. Chemosphere 180, 396-411 (2017).

32. Corsino, S. F., Capodici, M., Torregrossa, M. \& Viviani, G. Fate of aerobic granular sludge in the long-term: the role of EPSs on the clogging of granular sludge porosity. J. Environ. Manage. 183, 541-550 (2016).

33. Liu, Y.-Q., Liu, Y. \& Tay, J.-H. The effects of extracellular polymeric substances on the formation and stability of biogranules. Appl. Microbiol. Biotechnol. 65, 143-148 (2004)

34. Martins, A. M. P., Heijnen, J. J. \& Van Loosdrecht, M. C. M. Effect of dissolved oxygen concentration on sludge settleability. Appl. Microbiol. Biotechnol. 62, 586-593 (2003).

35. Jin, Y.-L. et al. Effect of DO concentration on biofilm structure and membrane filterability in submerged membrane bioreactor. Water Res. 40, 2829-2836 (2006).

36. Eaton, A. D., Clesceri, L. S., Rice, E. W., Greenberg, A. E. \& Franson, M. A. H. Standard Methods for the Examination of Water and Wastewater 21st edn (American Public Health Association, Washington DC, 2005).

37. Rumbaugh, K. P. (ed.) Quorum Sensing - Methods and Protocols (Springer, New York, 2011).

Open Access This article is licensed under a Creative Commons Attribution 4.0 International License, which permits use, sharing, adaptation, distribution and reproduction in any medium or format, as long as you give appropriate credit to the original author(s) and the source, provide a link to the Creative Commons license, and indicate if changes were made. The images or other third party material in this article are included in the article's Creative Commons license, unless indicated otherwise in a credit line to the material. If material is not included in the article's Creative Commons license and your intended use is not permitted by statutory regulation or exceeds the permitted use, you will need to obtain permission directly from the copyright holder. To view a copy of this license, visit http://creativecommons. org/licenses/by/4.0/.

C The Author(s) 2019 